\section{Sección 05}

doi: $10.35366 / 93481$
Vol. 9, Supl. 1 • Enero-Abril 2020. pp s30-s32 https://dx.doi.org/10.35366/93481

\title{
Trasplante renal. Aspectos pediátricos
}

\author{
Renal transplantation: Pediatric considerations
}

Mara Medeiros-Domingo*

* Nefróloga pediatra e Investigadora Nacional Nivel 2. Jefa de la Unidad de Investigación y Diagnóstico en Nefrología y Metabolismo Mineral Óseo. Hospital Infantil de México «Federico Gómez».

- El trasplante renal es el mejor tratamiento para los niños con enfermedad renal avanzada. Éste debe incluirse cuando el paciente pediátrico está en lista de espera y la tasa de filtración glomerular es menor o igual a $25 \mathrm{~mL} / \mathrm{min} / 1.73 \mathrm{~m}^{2}$.

- Las malformaciones urológicas son una de las causas más frecuentes de enfermedad renal en niños, y no suelen ser contraindicación de trasplante renal. Si un centro no tiene la capacidad de atender a pacientes con uropatías, éstos deben ser referidos a un centro pediátrico especializado en donde puedan recibir un trasplante.

- Los niños pueden ser seronegativos a virus como EBV (virus de Epstein-Barr) o CMV (citomegalovirus) y requerir una vigilancia más estrecha y/o tratamiento con profilaxis. El esquema de inmunizaciones debe estar lo más avanzado posible antes de un trasplante renal.

- Existen cambios en la biodisponibilidad de los medicamentos relacionados con la edad; además, el monitoreo terapéutico de fármacos como tacrolimus, sirolimus y micofenolato de mofetilo son útiles para ajustar las dosis en pacientes pediátricos.

El trasplante es el mejor tratamiento para los niños con enfermedad renal terminal porque mejora el crecimiento y desarrollo cognitivo como ninguna otra terapia de reemplazo renal. ${ }^{1}$

Con una vida media del injerto de 10 años, se espera que un niño que necesita terapia de reemplazo renal pueda necesitar dos o tres riñones a lo largo de su vida. Para ello, un trasplante de donante vivo relacionado tie- ne una mejor supervivencia que el de uno de donante fallecido, y esto puede deberse a que la mayoría es de alguno de los padres y, por lo tanto, tiene una mejor compatibilidad con el sistema del antígeno leucocitario humano (HLA) y un menor tiempo de isquemia fría. ${ }^{2,3}$ También, se tienen mejores resultados si el trasplante se realiza antes de que el paciente requiera procedimiento dialítico y cuando la tasa de filtración glomerular es de alrededor de $25 \mathrm{~mL} / \mathrm{min} / 1.73 \mathrm{~m}^{2}$.

No se tienen datos en la población mexicana, pero se estima que en Estados Unidos hay al menos 9,700 niños prevalentes con enfermedad renal crónica terminal (ERCT), y, por año, de 900 a 1,000 niños nuevos se agregan a la lista de espera; de esta cifra, 750 reciben trasplante renal cada año, siendo de 450-500 de donante fallecido. ${ }^{2}$

\section{Diferencias entre el trasplante} pediátrico y el de adultos

La causa principal de la ERCT en niños la constituyen las alteraciones congénitas de riñón y tracto urinario, seguida de las glomerulopatías. En los adultos, las causas principales son la diabetes y la hipertensión, por esto es más común que los niños requieran cirugía urológica previa al trasplante o cateterismo posterior; sin embargo, la malformación urológica no es contraindicación de trasplante renal. ${ }^{4}$ Existen pocas contraindicaciones absolutas de trasplante renal, aunque éstas pueden incluir procesos malignos activos, pruebas cruzadas positivas, hepatitis B crónica activa y enfermedad autoinmune activa. 
Los niños con mayor frecuencia son seronegativos para aquellos virus que pueden complicar el trasplante, como el citomegalovirus, virus BK y virus de EpsteinBarr, y para una infección primaria postrasplante que afecte el desenlace, como, por ejemplo, el desarrollo de enfermedad linfoproliferativa posterior al trasplante relacionada con EBV. ${ }^{4}$

Respecto al manejo de medicamentos, existen diferencias en la farmacocinética y farmacodinamia respecto al crecimiento y desarrollo del individuo. Dichas diferencias se deben principalmente a cambios en el peso relativo de los órganos respecto a su peso corporal, la proporción de agua extracelular/intracelular, que es mayor en tanto menos tenga edad el niño, y a la capacidad metabólica por las enzimas metabolizantes, las cuales van cambiando el tipo y expresión con la edad y pueden producir metabolitos activos o tóxicos (siendo diferentes en niños que en adultos, por ejemplo, los niños pequeños tienen mayor actividad del citocromo CYP3A7 y, a medida que crecen, van expresando más CYP3A4 y CYP3A5). ${ }^{5}$ También se ha encontrado una variación ontogénica en los transportadores como glicoproteína $\mathrm{P}$ y los transportadores de cationes y aniones orgánicos que influyen en la distribución y eliminación de los medicamentos. ${ }^{6}$ Además, en nuestro país, no se cuenta con formulaciones pediátricas para todos los inmunosupresores, por ejemplo, no existe aún la presentación de tacrolimus de 0.5 mg ni micofenolato de mofetilo en suspensión, y la manipulación de las formulaciones de adultos para dosificarlas introduce una fuente de error en medicamentos de estrecho índice terapéutico.

A pesar de estas diferencias, los niños menores de cinco años que reciben trasplante renal tienen la mejor supervivencia de todos los grupos etarios, esto es, de $80 \%$ en niños de 10 años; de $65 \%$ en los adultos de 35 a 49 años, y de $50 \%$ en los adolescentes de 12 a 17 años. ${ }^{2,3}$ En estos últimos, la menor supervivencia se ha atribuido a una mala adherencia terapéutica, por lo que son de suma importancia los programas de transición que van del cuidado pediátrico al de adultos. ${ }^{7}$

En referencia al estudio del receptor pediátrico, debe hacerse hincapié en el esquema de vacunación, ya que algunas vacunas se pueden adelantar desde los seis meses y se puede tratar de completar las vacunas de virus vivo; si se aplica una vacuna con virus vivo, el trasplante debe aplazarse por lo menos cuatro semanas. En cuanto a las vacunas de virus inactivados, éstas pueden aplicarse de tres a seis meses después del trasplante, ${ }^{8}$ además de que no suele requerirse curva de tolerancia a la glucosa; tampoco es útil la realización de cultivo de exudado nasal y faríngeo.

Causa de enfermedad renal crónica y otros aspectos del trasplante pediátrico

De acuerdo con el Hospital Infantil de México «Federico Gómez" y de los centros mexicanos que han reportado al RELATREP (Registro Latinoamericano de Trasplante Pediátrico), la causa más frecuente es desconocida $(60 \%) .{ }^{9}$

Más que una edad específica para el trasplante pediátrico, los equipos quirúrgicos suelen pedir un peso mínimo, el cual suele ser de entre 8 y $10 \mathrm{~kg}$ para los pacientes pediátricos. ${ }^{8}$ También es frecuente que los niños reciban el riñón de un adulto, y según sea el tamaño del receptor, puede decidirse hacer la anastomosis vascular a aorta y cava con abordaje transperitoneal en vez de hacerla en vasos iliacos. ${ }^{1}$ Los niños tienen un mayor riesgo de complicaciones vasculares y de lesión renal aguda, ya que debe perfundirse un órgano grande que secuestra mucho volumen circulante; el manejo de líquidos en el transoperatorio y postquirúrgico inmediato es crítico, ${ }^{8}$ y estos pacientes pediátricos pueden requerir apoyo ventilatorio por más tiempo que los adultos, ya que, si el injerto es grande, éste desplaza al hígado y diafragmas hacia arriba, dificultando la respiración y disminuyendo el retorno venoso por compresión de la vena cava inferior.

En aquellos pacientes que cursan con comorbilidades importantes, como anomalías cromosómicas, síndromes genéticos con discapacidad progresiva o irreversible, retraso grave en el neurodesarrollo o falla multiorgánica, cada uno debe ser evaluado por un equipo multidisciplinario para tomar la mejor decisión; lo ideal es que se haga de una manera sistematizada, transparente y sin discriminación. Además, se deben analizar las condiciones que puedan mejorar 0 empeorar un posible trasplante e involucrar a todos los especialistas que tengan que ver con el paciente (por ejemplo, gastroenterólogo, urólogo, cardiólogo, neurólogo, neumólogo, infectólogo, endocrinólogo, nutriólogo, psicólogo, trabajo social, entre otros) y el comité de ética del hospital para discutir el pronóstico, hacer un plan individualizado y tomar la mejor decisión para el paciente. De ser posible, el niño también debe participar en el proceso de decisión, siempre manteniendo una comunicación clara con la familia, pues, en ocasiones, puede decidirse esperar un tiempo y no realizar un trasplante anticipado, sino revalorar el caso periódicamente con el paciente en diálisis. ${ }^{10}$ 
Cuando un paciente pediátrico llegue por un posible trasplante, se recomienda que se envíe a valoración por el equipo de trasplante en cuanto el paciente tenga una tasa de filtración glomerular de $25 \mathrm{~mL} / \mathrm{min} / 1.73 \mathrm{~m}^{2}$. Si un centro no tiene la experiencia en el manejo de determinadas patologías, por ejemplo, en cirugías urológicas que se pudieran necesitar previo a un trasplante, es necesario referir al paciente a un centro especializado de forma oportuna.

En la actualidad, no sabemos cuántos pacientes de la lista de espera nacional son pediátricos; no obstante, ellos son quienes debieran tener preferencia para recibir un trasplante.

\section{REFERENCIAS}

1. Medeiros-Domingo M, Romero-Navarro B, Valverde-Rosas $\mathrm{S}$, Delgadillo R, Varela-Fascinetto G, Muñoz-Arizpe R. Trasplante renal en pediatría. Rev Invest Clin. 2005; 57 (2): 230-236.

2. Hart A, Smith JM, Skeans MA, Gustafson SK, Wilk AR, Robinson A et al. OPTN/SRTR 2016 Annual Data Report: Kidney. Am J Transplant. 2018; 18 Suppl 1: 18-113.

3. Dharnidharka VR, Fiorina P, Harmon WE. Kidney transplantation in children. N Engl J Med. 2014; 371 (6): 549-558.

4. Medeiros M, Castaneda-Hernández G, Ross CJ, Carleton BC. Use of pharmacogenomics in pediatric renal transplant recipients. Front Genet. 2015; 6: 41.
5. Kearns GL, Abdel-Rahman SM, Alander SW, Blowey DL, Leeder JS, Kauffman RE. Developmental pharmacology: drug disposition, action, and therapy in infants and children. N Engl J Med. 2003; 349 (12): 1157-1167.

6. Brouwer KL, Aleksunes LM, Brandys B, Giacoia GP, Knipp G, Lukacova $V$ et al. Human ontogeny of drug transporters: review and recommendations of the pediatric transporter working group. Clin Pharmacol Ther. 2015; 98 (3): 266-287.

7. Díaz-González de Ferris ME, Del Villar-Vilchis M, Guerrero R, Barajas-Valencia VM, Vander-Schaaf EB, de Pomposo A et al. Self-management and health care transition among adolescents and young adults with chronic kidney disease: medical and psychosocial considerations. Adv Chronic Kidney Dis. 2017; 24 (6): 405-409.

8. Hebert SA, Swinford RD, Hall DR, Au JK, Bynon JS. Special considerations in pediatric kidney transplantation. Adv Chronic Kidney Dis. 2017; 24 (6): 398-404.

9. Latin American Pediatric Nephrology Association; Latin American Pediatric Renal Transplant Cooperative Study. Latin American Registry of Pediatric Renal Transplantation 20042008. Pediatr Transplant. 2010; 14 (6): 701-708.

10. Goldberg AM, Amaral S, Moudgil A. Developing a framework for evaluating kidney transplantation candidacy in children with multiple comorbidities. Pediatr Nephrol. 2015; 30 (1): 5-13.

Correspondencia:

Dra. Mara Medeiros-Domingo

E-mail: medeiro.mara@gmail.com 